\title{
Capillaries in the epithelium of pterygium
}

\author{
Peter Seifert, Walter Sekundo
}

\begin{abstract}
Aim-To present new morphological observations of intraepithelial capillaries in pterygium and to provide some explanations for this phenomenon.

Methods-The ultrastructural features of pterygia from 26 patients were examined. Surgically excised tissue was processed for conventional light and transmission electron microscopy.

Results-Individual capillaries within the epithelium of the anterior half towards the head of pterygia were identified in 11 specimens out of 26 pterygia examined $(42.3 \%)$. The perivascular connective tissue of the intraepithelial capillaries contained fibroblasts, collagen fibrils, and elastin-like material. Epithelial cells surrounding these capillaries showed defects in the basal lamina in contrast with the continuous basal lamina of the endothelium. In the intercellular space of the epithelium an amorphous substance, occasional fibroblast processes, and collagen fibrils were frequently observed.

Conclusion-Capillaries in the epithelium of pterygia are rare, but not exceptional. The ingrowth of these vessels from the stroma into the epithelium can be interpreted as a reaction to hypoxia or deficiency of any other substance transported via the bloodstream. Apparently, the perivascular connective tissue can be used by ingrowing fibroblasts as a migration pathway. The migrating fibroblasts appear to use the defects of the epithelial basal lamina (whether partially or complete) in order to reach the intercellular space. It is possible that collagen fibrils in the epithelial intercellular space have been laid down by fibroblasts which contribute to the pathological dedifferentiation of the conjunctival epithelium.

(Br f Ophthalmol 1998;82:77-81)
\end{abstract}

\footnotetext{
Department of

Ophthalmology,

University of Bonn,

Germany

P Seifert

W Sekundo

Correspondence to:

P Seifert, $\mathrm{PhD}$,

Universitäts-Augenklinik,

Sigmund-Freud-Strasse 25

D-53105 Bonn, Germany.

Accepted for publication 27 August 1997
}

Alfried-Krup

Pterygium is a pathological alteration of the conjunctiva and cornea that is most frequently seen as a mass at the medial canthus, growing towards the central cornea. ${ }^{1}$ Neither the origin nor the cellular mechanisms of this disorder are known; however, there are several hypotheses. ${ }^{2}$ There is some evidence that ultraviolet light has a major impact on the pathogenesis of pterygium. ${ }^{4-7}$ However, unequivocal proof has not yet been reported. ${ }^{8}$ Several authors suggest that ultraviolet induced alteration of limbal stem cells is an important factor in the invasive nature of pterygium. ${ }^{79}$ Immunopathogenetic mechanisms ${ }^{10}$ and overexpression of the extracellular matrix ${ }^{11}$ have recently been discussed in relation to the pathogenesis of pterygium. We present new morphological observations of intraepithelial capillaries in pterygium. We also attempt to provide some explanations for this phenomenon and to comment on possible implications in the pathogenesis of pterygium.

\section{Material and methods}

We examined the anterior half (towards the head) of 26 pterygia by transmission electron microscopy (TEM). The specimens were obtained by routine surgical excision from both male and female patients ranging in age from 27 to 90 years. Pterygia were kept overnight in a fixative containing $2 \%$ glutaraldehyde, $2 \%$ paraformaldehyde, and phosphate buffer ( $\mathrm{pH}$ 7.3). They were then rinsed in 0.1 $M$ phosphate buffer and divided into small specimens measuring at most $2 \times 2.5 \mathrm{~mm}$. These small specimens were post-fixed in $2 \%$ osmium tetroxide for 2 hours, rinsed in phosphate buffer, dehydrated in ethanol, and embedded in Epon or Durcupan ACM. Serial sectioning was carried out by toluidine blue stained semithin sections with several ultrathin sections in between at different steps. Ultrathin sections (40-60 nm) were stained with uranyl acetate and lead citrate and examined with a Zeiss EM 109 transmission electron microscope.

Six controls were obtained from the perilimbal conjunctiva at the 12 o'clock position during routine cataract surgery. This area was chosen because it is protected from the ultraviolet light by the upper lid. Control specimens were prepared for TEM in the same manner as mentioned above.

\section{Results}

The stroma in each anterior half towards the head of the pterygium was highly vascularised (Fig 1(1)). In some parts rows of capillaries were observed either directly under the epithelium or as capillarised connective tissue papillae drawn into the epithelium. Subepithelial capillaries were surrounded by an amorphous substance and multiple layers of endothelial cell basal lamina (Fig 1(2)) in the majority of cases. In addition, 11 out of 26 
specimens $(42.3 \%)$ revealed individual capillaries within the epithelium of pterygia in their anterior part towards the head. In serial semithin sections an unequivocal identification of capillaries was possible, when the latter contained erythrocytes in the lumen. Capillaries without red blood cells were seen on ultrathin sections by TEM. No correlation between patient age or sex and intraepithelial vascularisation was obvious.

These intraepithelial capillaries were entirely surrounded by epithelial cells (Fig 1(3)). Some capillaries were associated with a thin cleft (minimal width $2 \mu \mathrm{m}$ ) in the surrounding epi-

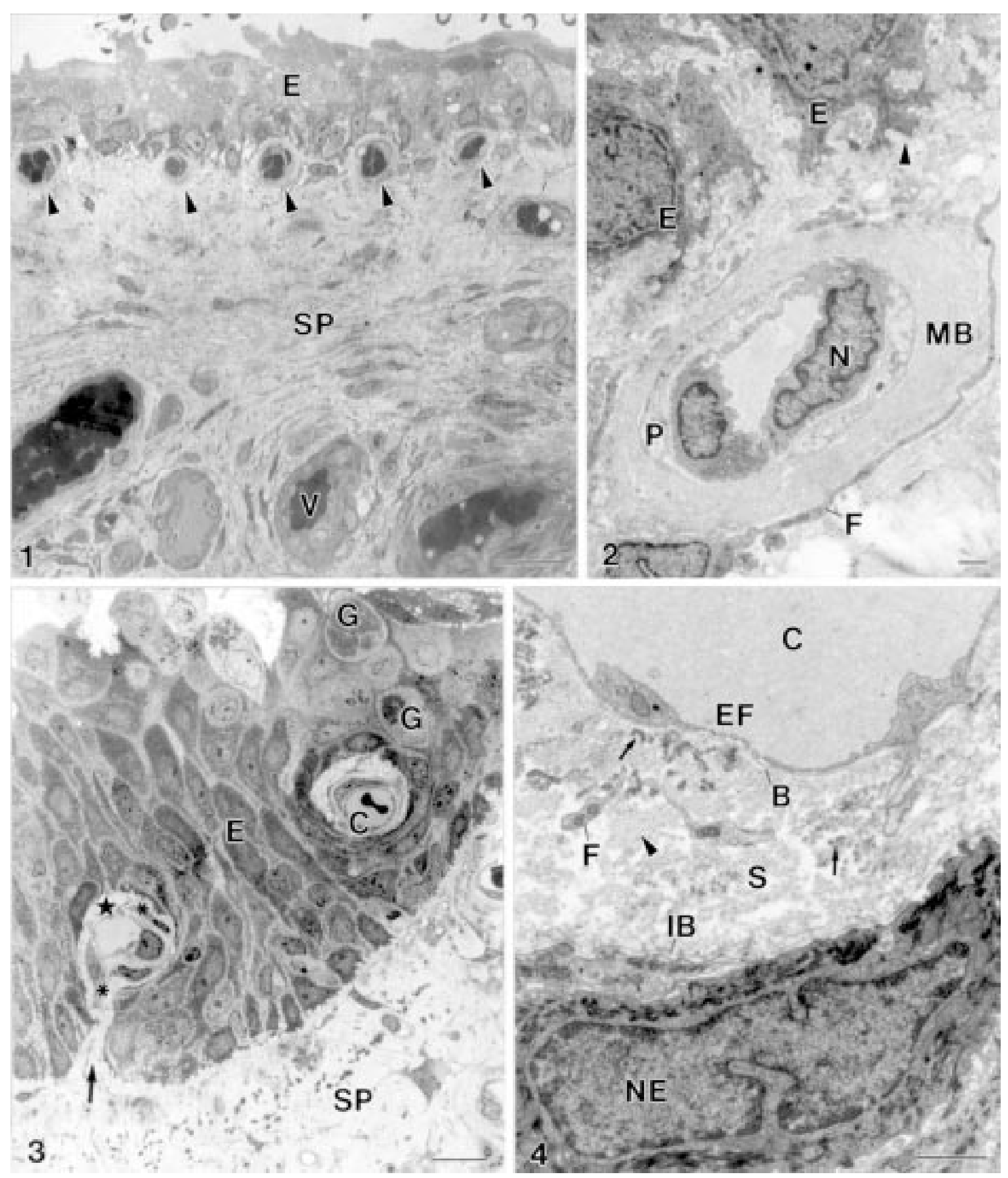

Figure 1 (1) The stroma of the pterygium (SP) is highly vascularised (V). Subepithelial capillary (arrowhead), epithelium (E). Bar $=20$ um.

(2) Subepithelial capillary. Subepithelial basal lamina (arrowhead), epithelial cell (E), cellular extension of a fibroblast (F), multilamellar basal lamina of a capillary $(M B)$, endothelial cell nucleus $(N)$, pericyte $(P)$. Bar $=1 \mu \mathrm{m}$. (3) Intraepithelial capillary $(C)$ and a capillary with a hilus-like connection (arrow) between the perivascular connective tissue (star) and the subepithelial stroma of pterygium (SP). Fibroblast (asterisk), goblet cell (G), epithelium (E). Bar $=10 \mu \mathrm{m}$. (4) The perivascular stroma (S) of intraepithelial capillaries (C) is outlined by an endothelial basal lamina (B) and an "internal" epithelial basal lamina (IB). The perivascular stroma contains cellular processes of fibroblasts (F), collagen fibrils (arrowhead) and electron dense elastin-like material (arrow). Endothelial cell fenestration (EF), epithelial cell nucleus (NE). Bar $=1 \mu \mathrm{m}$. 
thelium, which connected the perivascular connective tissue with the stroma of the pterygium (Fig 1(3)). Fibroblasts were observed in almost all of those clefts as well as in the perivascular space of the intraepithelial capillaries (Fig 1(3)). Capillary endothelial cells had the usual appearance with normal organelles, occasional fenestrations, pinocytotic pits, and vesicles (Figs 1(4) and 2(5)).
Pericytes were also present. The endothelial basal lamina did not reveal any morphological defects in the multiple sections examined and was either single or multilayered (Fig 2(5)).

The perivascular stroma appeared as a thin eccentric connective tissue layer between the basal laminae of the capillary and the epithelium. This layer contained cell processes of fibroblasts as well as collagen fibrils and
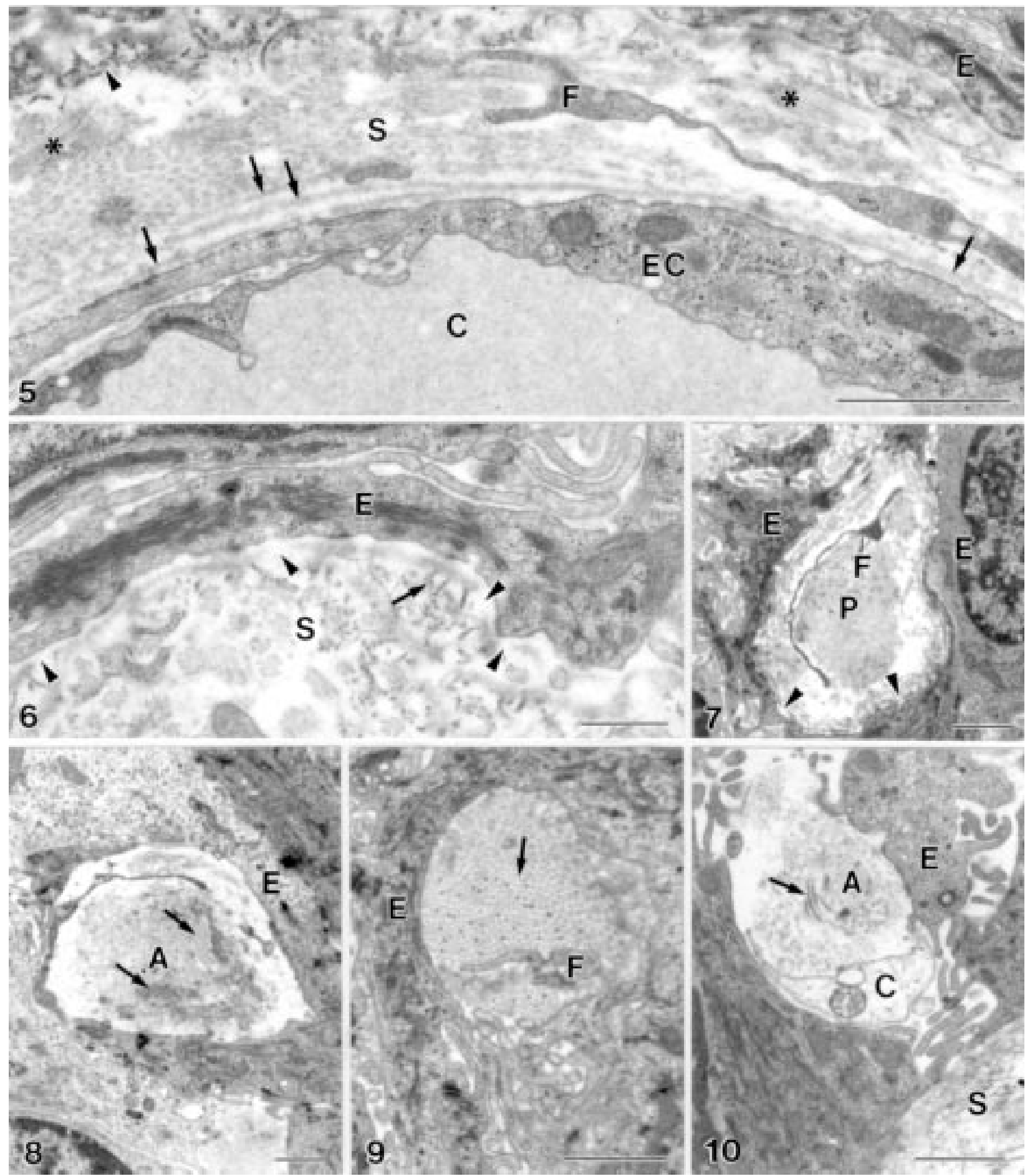

Figure 2 (5) The endothelial basal lamina of the intraepithelial capillaries (C) is partially single layered and partially multilayered (arrow). Anchoring fibrils (arrowhead), wide spaced collagen fibrils (asterisk), epithelial cell (E), endothelial cell (EC), extension of fibroblast (F), perivascular stroma (S). Bar $=1 \mu \mathrm{m}$. (6) Defects in the "internal" epithelial basal lamina (arrowhead). Anchoring fibril (arrow), epithelial cell (E), perivascular stroma (S). Bar $=0.5 \mu \mathrm{m}$. (7) Defects (arrowhead) in the epithelial basal lamina at a stromal micropapilla (P). Epithelial cell $(E)$, extension of fibroblast $(F)$. Bar $=1$ $\mu m .(8-10)$ The enlarged intercellular space within the epithelium contains structures not typical for epithelia with collagen fibrils (arrow) and fibroblast processes $(F)$. Amorphous material $(A)$, non-identified cell $(C)$, epithelial cell $(E)$, stroma $(S)$. Bar $=1 \mu \mathrm{m}$. 
elastin-like electron dense material (Figs 1(4) and 2(5)). Parallel aligned, highly organised collagen fibrils were seen side by side with wide spaced collagen fibrils (Fig 2(5)). Anchoring fibrils were associated with epithelial basal lamina (Fig 2(6)). The internal epithelial basal lamina showed prominent defects in cross sections, but how long these defects were along the course of the intraepithelial vessels was not clear (Fig 2(6)). In contrast, the subepithelial basal lamina was morphologically intact in all cases. The only exception was a stromal papilla, where the basal lamina was interrupted in several places (Fig 2(7)).

The intercellular space of the epithelium in the examined pterygia was partially filled with an amorphous substance. In addition, cellular processes of fibroblasts and collagen fibrils were occasionally seen in the area of ingrowing capillaries, projecting into the intercellular space (Fig 2(8-10)).

As already reported in the literature on the anatomy of the human conjunctiva, ${ }^{12-14}$ we did not find intraepithelial capillaries in any of the control specimens examined.

\section{Discussion}

A substantial number of positive samples in our study indicate that intraepithelial capillaries are rare, but not exceptional. There is no doubt that vascularised stratified epithelium is, with a few exceptions, a pathological entity. Indeed, in addition to the present report on vascularisation of the epithelium in pterygium, vascularisation of the conjunctival epithelium has been described by Steuhl, but only after lime burn. ${ }^{14}$

Neovascularisation is a reaction to oxygen deficiency and ischaemia. This reaction is triggered by several angiogenic and inhibitory factors. For instance, the expression of vascular endothelial growth factor (VEGF) can be induced by oxygen deficiency. ${ }^{15-17}$ In nonvascularised tissues like stratified epithelium, neovascularisation becomes suppressed. Normal conjunctival epithelium is also not vascularised. ${ }^{12-14}$ We do not know which signals induce angiogenic or inhibit antiproliferative factors in the epithelium of pterygium, nor can we exactly name (based on our study) the steps preceding epithelial vascularisation in the pathogenesis of pterygium.

Vascularised stratified epithelia as a nonpathological finding are extremely rare in the entire animal kingdom. In humans we are aware of just one single location for vascularised stratified epithelium, namely the endolymph secreting stria vascularis in the inner ear. ${ }^{18}$ The perivascular connective tissue of these strial capillaries consists of mere "fine fibrillar elements", while endothelial and internal epithelial basal laminas appear to be largely fused. ${ }^{18}$ The perivascular space of the epithelial capillaries in pterygium is somewhat different. Indeed, this space seems to be wide enough to serve as a migration pathway for ingrowing fibroblasts. Fibroblasts appear to seek an appropriate place to invade the epithelium and probably do so in the stromal papillae which, as we demonstrated, contain cellular processes.
Interconnections between the perivascular stroma of some intraepithelial capillaries and the substantia propria of pterygium may indicate "epithelial gates" for incoming or outcoming capillaries.

The next question that arises is what role does the perivascular ingrowing fibroblasts play in the pathogenesis of pterygium? Rows of fibroblasts have been described in the stromal head of pterygium. ${ }^{419}$ We have also observed this phenomenon (unpublished data). Cameron believes that these cells play an important role in the invasive nature of pterygium. ${ }^{419}$ Another hypothesis, supported by immunohistochemical investigations ${ }^{9}$ and by a theoretical model for pterygium formation, ${ }^{7}$ ascribes a critical role to the alteration of limbal stem cells. Karukonda et al showed no difference in the cellular proliferation pattern between pterygial and conjunctival tissue, ${ }^{11}$ suggesting that the overexpression of the extracellular matrix predominates over the cellular proliferation in the pathogenesis of pterygium. ${ }^{11}$ Other recent publications implicated immunopathogenetic mechanisms in the process of pterygium formation. ${ }^{1020}$

We believe that the fibroblasts we found extend their influence far beyond the perivascular space into epithelium. These fibroblasts may also play a major part in the dedifferentiation of the epithelium since collagen fibrils in the intercellular space indicate fibroblastic activity and are never seen in normal epithelia. We assume that cell processes or possibly entire fibroblasts invade the intraepithelial space from the perivascular space via the defects in the basal lamina. Moreover, it is possible that fibroblasts create these defects similar to an identical phenomenon in stromal papillae occupied by fibroblasts.

Our observations of intraepithelial capillaries and collagen producing fibroblasts in the intercellular space show that certain and defined epithelial characteristics become fundamentally disorganised in pterygium at an unknown stage in the pathogenesis of this condition.

Presented at the 1997 annual ARVO meeting in Fort LauderPresented at the 1997
dale, Florida, USA.

The authors wish to thank Karin Loeffler, MD, for critically reviewing the manuscript and Ute Komnick, Parand Pour reviewing the manuscript and Ute Komnick, Parand Pour The work was supported by 'Aktion Kampf der Erblindung'.
Thez, and Claudine Strack for excellent technical assistance.

1 Fuchs E. Über das Pterygium. Graefes Arch Ophthalmol 1892;38:1-90.

2 Hill JC, Maske R. Pathogenesis of pterygium. Eye 1989;3:218-26

3 Coroneo MT. Pterygium as an early indicator of ultraviolet insolation: a hypothesis. Br f Ophthalmol 1993;77:734-9.

4 Cameron ME. Pterygium throughout the world. Springfield, IL: Charles C Thomas, 1965.

5 Moran DJ, Hollows FC. Pterygium and ultraviolet Moran DJ, Hollows FC. Pterygium and ultraviolet radiation:

6 Taylor HR, West SK, Rosenthal FS, Munoz B, Newland HS, Emmett EA. Corneal changes associated with chronic UV irradiation. Arch Ophthalmol 1989;107:1481-4.

7 Kwok LS, Coroneo MT. A model for pterygium formation. Cornea 1994;13:219-24.

8 Dolin PJ, Johnson GJ. Solar ultraviolet radiation and ocular disease: a review of the epidemiological and experimental evidence. Ophthalmic Epidemiol 1994;1:155-64.

9 Dushku N, Reid TW. Immunohistochemical evidence that human pterygia originate from an invasion of vimentinexpressing altered limbal epithelial basal cells. Curr Eye Res 1994;13:473-81.

10 Ioachim-Velogianni E, Tsironi E, Agnatis N, Datseris G, Psilas K. HLA-DR antigen expression in pterygium epithelial cells and lymphocyte subpopulations: an immunohistochemistry study. Ger f Ophthalmol 1995;4:123-9. 
11 Karukonda SR, Thompson HW, Beuerman RW, Lam DS, Wilson R, Chew SJ, et al. Cell cycle kinetics in pterygium at

12 Virchow H. Mikroskopische Anatomie der äußeren Augenhaut und des Lidapparates. In: Graefe-Saemisch, ed. Handbuch der Augenheilkunde. 1 Bd, 1 Abt, Kap 2. Leipzig 1910:1-618.

13 Rohen JW. Zur funktionellen Morphologie der Conjunctiva. Fortschr Ophthalmol 1986;83:13-24.

14 Steuhl KP. Ultrastructure of the conjunctival epithelium. In: Straub W, ed. Developments in ophthalmology. Basel: Karger, 1989:1-99.

15 Ladoux A, Frelin C. Hypoxia is a strong inducer of vascular endothelial growth factor mRNA expression in the heart. Biochem Biophys Res Commun 1993;195:1005-10.
16 Brogi E, Wu T, Namiki A, Isner JM. Indirect angiogenic cytocines upregulate VEGF and bFGF gene expression in vascular smooth muscle cells, whereas hypoxia upregulates VEGF expression only. Circulation 1994;90:649-52.

17 Minchenko A, Bauer T, Salceda S, Caro J. Hypoxic stimulation of vascular endothelial growth factor expression in vitro and in vivo. Lab Invest 1994;71:374-9.

18 Hinojosa R, Rodriguez-Echandia EL. The fine structure of the stria vascularis of the cat inner ear. Am $\mathcal{f}$ Anat 1966;118:631-64.

19 Cameron ME. Histology of pterygium: an electron microscopic study. Br F Ophthalmol 1983;67:604-8.

20 Liu L, Yang D. Immunological studies on the pathogenesis of pterygium. Chin Med Sci f 1993;8:84-8. 